\title{
Prevalence and Mental Health Function of Resilience in Condition of Military Siege and Violence in a Palestinian Community Sample
}

\author{
Thabet AA ${ }^{1}$, Ahmad Abu Tawahina ${ }^{2}$, Raija-Leena Punamäki ${ }^{3}$ and Panos Vostanis ${ }^{4 *}$
}

${ }^{1}$ Child and Adolescent Psychiatry, Al Quds University, School of Public Health, Child Institute-Gaza, Finland

${ }^{2}$ Gaza Community Mental Health Programme, Finland

${ }^{3}$ School of Social Sciences and Humanities/ University of Tampere-Finland

${ }^{4}$ Professor of Child Psychiatry, Finland

\begin{abstract}
Aims: The study had two aims: First, we assess the prevalence of resilience based on the person-based classification depicting a balance between the severity of trauma and occurrence of PTSD. Second, we examine the role of resilience characteristics of commitment, control and challenge in protecting children's mental health from negative trauma impacts.

Methods: The participants were 386 Palestinian children and adolescents from Gaza (age 13.41+2.96, 52.07\% boys and $47.93 \%$ girls). The results revealed a $25 \%$ prevalence of resilient children, and resilience was more common in well-educated families and children from geographical areas exposed to heavily Israeli shelling and destruction. Children were interviewed by sociodemographic scale, Gaza Traumatic Events Checklist, Child Depression and Anxiety Scale, UCLA PTSD Index for DSM-IV-Adolescent Version, and Resilience Attitude Scale.

Results: There were generally no gender differences in the exposure to traumatic events, as all. Neither were there gender differences in the mean number of traumatic events related to Israeli military violence or Palestinian factional fighting. According to the DSM-IV criterion, $12.4 \%$ of the children and adolescents reported probable PTSD, and $22.37 \%$ filled the two criteria partial PTSD, and $26.7 \%$ the one criteria partial PTSD (re-experiencing or avoidance or hyper arousal). More than a third ( $38.4 \%$ of the children did not have PTSD. There were no significant differences between boys and girls in PTSD. For depression and anxiety, boys and girls did not differ in the levels of PTSD, depressive and anxiety symptoms. Also only one marginal gender difference was found concerning resilience characteristics: girls reported more feelings of control than boys. The results revealed that $25.0 \%$ of the participants was classified as resilient indicating presence of high exposure to traumatic events and absence of PTSD and $22.2 \%$ as traumatized, i.e., presence of both high exposure to trauma and occurrence of PTSD. Of the children $12.7 \%$ were classified as vulnerable, and $40.1 \%$ were spared of both high trauma and PTSD. As hypothesized, resilience characteristics protected children's mental health from trauma, e.g., military trauma was less associated with PTSD and anxiety among children showing high commitment. Discussion focuses on specific functions of resilience in the context of different kind of traumatic events of war, political and military violence.
\end{abstract}

Keywords: Military violence; Palestinians; Resiliency; Trauma; War

\section{Introduction}

In conditions of war and military violence, children need remarkable resources, strengths and invincibility to guarantee their basic adjustment and healthy development. Resilience is conceptualized as a capacity to return into normal functioning or even blossom after severe trauma. Resilience also refers to the absence of psychiatric or psychosocial problems and presence of developmental competences [1-3].

There is a discussion whether resilience or traumatisation are the norm in life-endangering conditions of war and terrorism [4]. Empirically neither resilience nor excessive psychiatric disorders is the most prevalent among trauma surviving children. Instead, they show various ways of recovery, and attempts to cope and protect their well-being and psychological integrity. A majority of children shows excessive fears and posttraumatic symptoms (PTSD) and cling to parents in acute life danger, but most of them gradually recover if psychological and social resources are available [5,6]. It is thus important to know about child- and environment-related factors that contribute to the resilience. The present study analyses resilience prevalence and function among Palestinian children who lived in conditions of military violence and siege in Gaza.

Children's resilience has been conceptualized and assessed in three different ways. First, the classic definition of resilience suggests a person-based classification or typology depicting the balance between the severity of trauma and emergence of psychiatric disorder [3]. In addition to identifying resilient individuals, i.e., those with high exposure to trauma and high competence, the classification provides also prevalence of children who are traumatized (both severe trauma and severe disorders), vulnerable (high level of disorders without trauma exposure) and spared (saved from both trauma and disorders). We could find two studies reporting the prevalence of children's resilience based on the person-related classification. A follow-up study in American families with chronic stress and adversities documented the prevalence of $22 \%$ of resilient children, and $7 \%$ vulnerable, $13 \%$ traumatized and 58\% spared children [7]. Interestingly, similar

*Corresponding author: Panos Vostanis, Professor of Child Psychiatry, Finland Tel: 0116 2252885; Fax: 0116 2252881; E-mail: pv11@leicester.ac.uk

Received January 27, 2015; Accepted March 27, 2015; Published April 03, 2015

Citation:Thabet AA, Tawahina AA, Punamäki RL, Vostanis P (2015) Prevalence and Mental Health Function of Resilience in Condition of Military Siege and Violence in a Palestinian Community Sample. J Psychiatry 18: 274 doi: 10.4172/2378-5756.1000274

Copyright: (c) 2015 Thabet AA, et al. This is an open-access article distributed under the terms of the Creative Commons Attribution License, which permits unrestricted use, distribution, and reproduction in any medium, provided the original author and source are credited 
prevalence of resilience (21\%) was found among Palestinian children in conditions of military occupation, whereas $23 \%$ were classified as both traumatized and vulnerable, and a third was spared from both military trauma and psychological disorders [8].

Second, a variable-based approach to resilience seeks for children's positive experiences, resources and competence. The beneficial issues can be available in family, school and society, characterize children themselves $[9,10]$. There is augmenting evidence that supportive parent-child relations [11,12]. Encouraging school atmosphere and high academic achievements, and supportive societies and respect for children's rights contribute to resilience [13,14].

High self-esteem, creativity, commitment and strong believes in one's ability to cope with hardships are commonly found among resilient children $[13,15]$. Research further suggest that resilient children are curious, prosocial and able and willing to create novel, flexible solutions for problems [7,11]. Commitment and thrust in oneself and others make it possible to plan for future and share aspirations with others. Moreover, resilient children are able adequately to process stressful and traumatic experiences and seek for realistic causal explanations, without being overwhelmed by guilt and fear [16]. The feeling of control, whether real or illusory can be decisive for the recovery among children struggling to overcome traumatic experiences [17]. Ability to control and regulate traumatic memories forms a protective shield against PTSD and other trauma-related psychiatric distress $[18,19]$. Finally, there are some hypotheses that children's temperament such as novelty seeking, high stimulus threshold and easy attenuating of arousal would be one of the secrets of resilience [20,21]. This means that some children experience traumatic events and even adversities as a challenge, which in turn indicates that resilience can depend on the goodness of fit between individual needs and environmental demands.

Finally, a part of research conceptualizes resilience as a lack of (expected) PTSD or other psychiatric symptoms. After the 9/11 terrorist attack, it was reported, e.g., that $63 \%$ of adult survivors were resilient, indicating that they did not develop PTSD [22]. Similarly, Israeli adolescents who did not show PTSD after being personally exposed to terrorist attacks were called resilient [23]. In these studies the reasons for resilience are conceptualized as a list of post-hoc characteristics such as variety of beneficial appraisals, personality and national history, supporting networks, competence and individual and societal hardiness.

\section{Aims of the Study}

This study applies both person- and variable-based concepts of resilience among children living in life-endangering conditions and being personally exposed to military violence. First, we assess the prevalence of resilience based on the person-based classification depicting a balance between the severity of trauma and occurrence of PTSD. Second, we examine the role of resilience characteristics of commitment, control and challenge in protecting children's mental health from negative trauma impacts. We hypothesize that traumatic events of military violence and fighting do not associate with PTSD, depressive and anxiety symptoms among children who show high levels of these three resilience characteristics.

\section{Method}

\section{Participants and procedure}

This was descriptive analytic study. The participants were 386 Palestinian boys (52.07\%) and girls (47.93\%) living in Gaza Strip. They were 8 - 18 years old $(\mathrm{M}=13.41 \pm 2.96)$, and there were no gender differences according to age $\mathrm{F}(1,384)=0.42$, $\mathrm{p}=\mathrm{ns}$.). The original sample consisted of 400 children, and the drop out was thus $3.50 \%$ consisting of 14 children who did not complete the questionnaires during the interviews in their homes in Gaza Strip- Palestine. The sample selection was done using EPI 6 program for sampling process.

The sample was randomly selected from the population census representing the five areas of the Gaza Strip and including two-parent families. In selecting the children each area was divided into blocks and from each block one street was chosen, and from each street every 15th home was approached for the data collection. The field work was conducted by professionals who had experiences in working with children and families. They were 5 social workers, 4 psychologist, 2 nurses, and 3 physicians working in Gaza Community Mental Health Program (GCMHP). They were trained for research and data collection, and they visited the families according to prepared lists of number of children selected to the study. Ethical approval was obtained from the responsible body in the Ministry of Health in Gaza Strip. The field workers presented an information letter to the parents, and if agreed, they obtained a written permission for their children's participation. Children were interviewed individually in their homes and each interview lasted approximately 30 minutes. The interviewers informed children that there was no right or wrong answers, provided guidance in filling-up the scales. Children and parents were also informed that that they were free to withdraw from the study at any time. Sociodemgraphic data was collected from mothers, while exposure to trauma, PTSD, anxiety, resilience was collected through face to face interview with children. The exclusion criteria include children with disability, mental retardation, and diagnosed psychiatric disorders. The data collection was done between March and April 2008.

\section{Instruments}

Sociodemographic information was collected from parents and information about traumatic events, mental health and resilience from children themselves. Sociodemographic characteristics include sex, age, and place of residence, and education of the family head.

Traumatic events were assessed by two check lists that reflected the nature of violence, trauma and losses during the two-year of Israeli siege of the Gaza strip. First, Israeli military violence was assessed by the Gaza Traumatic Events Checklist for Israeli Violence [24] consisting of 28 items covering three domains of events typical for the Israeli siege: (1) witnessing personally acts of violence (e.g., killing of relatives, home demolition, bombardment, and injuries), (2) having experiences of loss, injury and destruction in family and other close persons, and (3) being personally the target of violence (e.g., being shot, injured, or beaten by the soldiers). Second, Palestinian factional fighting was assessed by the Gaza Traumatic Events Checklist for Factional Fighting consisting of 20 items covering similar domains of traumatic events due to the regional conflict between Fatah and Hamas faction fighting in the Gaza Strip in June 2007. The content of traumatic events related to Israeli military violence and Palestinian factional fighting are shown in Table 1. In both checklists children were asked whether they had been exposed to each of these events: ${ }^{(}{ }^{)}{ }^{n} \mathrm{O}^{\prime}(1)$ yes during the last 12 months. Gaza Traumatic Events Checklist for Israeli Violence Cronbach's alpha was 0.88 and 0.91 for Gaza Traumatic Events Checklist for Factional Fighting.

Separate sum variables were constructed by accounting the occurrences of the traumatic events for Israeli military violence (ranging between 0-28), Palestinian factional fighting (0-20), and total traumatic events (3-48). To construct the $2 \times 2$ resilience classification, 
Citation: Thabet AA, Tawahina AA, Punamäki RL, Vostanis P (2015) Prevalence and Mental Health Function of Resilience in Condition of Military Siege and Violence in a Palestinian Community Sample. J Psychiatry 18: 274 doi:10.4172/2378-5756.1000274

the total traumatic events -variable was dichotomized to low (2-5 events) and high (6-18 events) levels. It would have been ideal to construct a dichotomized variable indicating zero-trauma vs. yestrauma, but there were only 2 children who had not reported exposure to traumatic events. The cut-off points were decided according to empirical statistics and earlier knowledge about cumulative trauma exposure in war conditions [25].

PTSD-symptoms were measured by the UCLA PTSD Index for DSM-IV-Adolescent Version [26]. The scale comprises 22 self-report items based on DSM-IV PTSD symptom criteria: re-experiencing symptoms (e.g., "I act or feel like it is happening all over again"), avoidance symptoms (e.g., "I have trouble remembering important parts of what happened"), and hyperarousal symptoms (e.g., "I watch out for danger or things I'm afraid of"). Children were asked to indicate the frequency of symptoms experienced on a 5-point Likert scale ranging from 0 (never) to 4 (most of the time). A PTSD symptom severity scale was computed as the sum of the responses to the 20 (of 22) items and categorical prevalence score. The UCLA PTSD Index has been widely used among children and adolescents in the Middle East and elsewhere [27-30]. The original English version of the PTSD scale had Cronbach's $\beta$ of .90 , and good to excellent test-retest reliability [31]. The reliability of our Arabic version of the PTSD scale Cronbach's in this study $\alpha=0.89$; split half $=0.82$.

Child Depression and Anxiety Scale The scale consists of 25 items of depressive and anxious symptoms. Depression items were drawn from the self-report scale of the Children's Depression Inventory, and anxiety items form the Revised-Children's Manifest Anxiety Scale $[32,33]$. Children were instructed to estimate whether they had had the symptom during the last month. No (0) or Yes (1). Sum variables were constructed to indicate children's depressive symptoms including somatic dimensions (13 items, e.g, "I feel sadness when waking up in the morning"; I do not have appetite for food), anxiety and fears (12 items, e.g., "I am worried about many things"; "I am afraid of unknown"). The internal consistency were good for the Arabic version of the total scale (Cronbach's alpha $=0.77$; split half $=0.74$ ) and depressive symptoms symptoms (Cronbach's $\alpha=72$ ), but not for anxiety symptoms (Cronbach's $\alpha=0.65$ ).

Resilient attitudes were measured by The Resilience Attitude Scale by (Mekhaemer, 2002) [34]. The scale contains 47 items covering the resilience characteristics of commitment (items: $1,4,7,10,16,19,22,25$ $28,31,34,37,40,43,46$ ), control (items: $2,5,8,11,14,17,20,23,26,29,32,35,3$ $8,41,44$ ), and willingness to take challenges (items: $3,6,9,12,15,18,21,24$, $7,30,33,36,39,42,45,47)$.

Children were instructed to evaluate on a three-point scale how well the feelings and thoughts describe theirs: not at all (0), to some extent (1), and very well (2). The total score ranges from $0-141$, with higher score reflecting greater resilience. Three subscales were constructed: Commitment (16 items, e.g., "I care much for problems and things that happen around me"; "I care for all possible initiative that may help my family and community", Control (14 items, e.g., "I think luck and accidents play major role in my life"; "I think people's life is influenced by external forces that they cannot control") and Challenge (17 items, e.g., "I am curious to know the unknown"; "When I have solved one problem, I enjoy moving into to solving another one". The Resilience attitudes -scale has been validated in Arabic culture in Egypt [34] and in Gaza Strip, and has been found reliable among Palestinian children in Gaza Strip (Cronbach's alpha $=0.84$ and split half $=0.84$ ) $[35,36]$. In this study the internal consistencies were good for Commitment
(Cronbach's $\alpha=0.80$ ). However, they were not satisfactory for Control (Cronbach's $\alpha=0.64$ ) and Willingness to take challenges (Cronbach's $\alpha=0.60)$ scales.

Resiliency classification was constructed as a balance between the severity of trauma exposure and PTSD. The cross tabulation of the 10 dichotomized total sum of traumatic events and PTSD classification $(0=$ no PTSD; $1=$ partial and full-blown $)$ resulted in four groups: Resilient children (high level of traumatic events and absence of PTSD), Vulnerable children (low level of traumatic events and presence of PTSD), Traumatized children (high level of traumatic events and presence of PTSD), and Spared children (low level of traumatic events and absence of PTSD). Resiliency classification was constructed as a balance between the severity of trauma exposure and PTSD. The cross tabulation of the dichotomized total sum of traumatic events and PTSD classification ( $0=$ no PTSD; =partial and full-blown) resulted in four groups: Resilient children (high level of traumatic events and absence of PTSD), Vulnerable children (low level of traumatic events and presence of PTSD), Traumatized children (high level of traumatic events and presence of PTSD), and Spared children (low level of traumatic events and absence of PTSD).

\section{Statistics analyses}

Cross table $s$ with Pearson $\chi^{2}$-statistics were applied to analyse the associations between demographic factors and psychiatric symptoms, and gender differences in exposure to traumatic events. The independent variable for this study was the traumatic events and dependent variables were PTSD, Depression, Anxiety, and resilience. T-tests were applied to analyse gender differences in psychiatric symptoms. To analyse the protective role of resilience characteristics of commitment, control and challenge, we used hhierarchical multiple regression analyses with main and interaction effects. The estimated main effects indicate direct associations between resilience characteristics and psychiatric symptoms, and trauma $\mathrm{X}$ resilience characteristics-interaction effects the protective power of commitment, control and challenge in attenuating the links between trauma and symptoms. The dependent variables were PTSD, depressive and anxiety symptoms. In the Step I, demographic factors were entered, in the Step II, the two variables of traumatic events (Israeli military violence and Palestinian factional fighting) were entered, followed by resilience characteristics at Step III. In the Step IV, the interaction terms between Israeli military violence and resilience characteristics, and in the Step V, the corresponding interactions between the Palestinian factional fighting and resilience characteristics were entered. All variables used in the construction of the interaction terms were first centered (the score-mean-value) in order to avoid multicollinearity between predictor variables [37].

\section{Results}

\section{Descriptive statistics}

The participating children and adolescents presented the relative share of residents in the five areas in the Gaza Strip. More than a third (36.79\%) was from Gaza City, a fifth (20.73\%) from the other large city, Khan Younis, and $16.58 \%$ from the North and $13.99 \%$ from the Middle area of Gaza. Southern area, Rafah was presented by $11.92 \%$. About a half $(57.25 \%)$ of the participants lived in cities, $32.64 \%$ in refugee camps and $10.10 \%$ in villages. Three quarters $(73.58 \%)$ of them were offspring of 1948 refugees from the historical Palestine and $26.42 \%$ were Gaza citizens. These distributions correspond with general population census in the Gaza Strip [37]. 
Citation: Thabet AA, Tawahina AA, Punamäki RL, Vostanis P (2015) Prevalence and Mental Health Function of Resilience in Condition of Military Siege and Violence in a Palestinian Community Sample. J Psychiatry 18: 274 doi:10.4172/2378-5756.1000274

Page 4 of 9

Table 1 presents the percentages of the traumatic events of Israeli military violence and Palestinian factional fighting. Of the military violence, the most common traumas were the sonic boom sounds caused by jetfighters (90\%), hearing of shelling by artillery $(87 \%)$ and witnessing assassination of close people by targeted rockets $(85 \%)$. Of the factional fighting, the most common traumas were hearing of shooting and gunfire in the streets (87\%) and deprivation of water or electricity (55\%). There were generally no gender differences in the exposure to traumatic events, as all $\beta^{2}$-values were non-significant. Neither were there gender differences in the mean number of traumatic events related to Israeli military violence [boys $M=9.96, S D=6.19$; girls $\mathrm{M}=10.43, \mathrm{SD}=6.65 ; \mathrm{t}(384)=-0.72, \mathrm{p}=.47]$ or Palestinian factional fighting [boys $\mathrm{M}=7.17, \mathrm{SD}=4.7$; girls $\mathrm{M}=7.70, \mathrm{SD}=4.95$; $\mathrm{t}(384)=-1.06$, $\mathrm{p}=.29$.

According to the DSM-IV criterion, $12.4 \%(n=48)$ of the children and adolescents reported probable PTSD, and $22.37 \%(n=86)$ filled the two criteria partial PTSD, and $26.7 \%(n=103)$ the one criteria partial PTSD (re-experiencing or avoidance or hyperarousal). More than a third $(38.4 \%, \mathrm{n}=149)$ of the children did not have PTSD. There were no significant differences between boys and girls in PTSD $\left(\chi^{2}=4.70, p=n s\right.$, $\mathrm{N}=386$ ) or in PTSD symptoms. Table 2 shows that boys and girls did

\begin{tabular}{|c|c|c|c|c|c|}
\hline & \multicolumn{2}{|c|}{$\begin{array}{l}\text { Israeli military } \\
\text { violence }\end{array}$} & \multicolumn{2}{|c|}{$\begin{array}{c}\text { Palestinian } \\
\text { factional fighting }\end{array}$} & \multirow[b]{2}{*}{$P$ value } \\
\hline & $\%$ & $N$ & $\%$ & $\mathbf{N}$ & \\
\hline 1. Sonic booms of jetfighters & 328 & 90.4 & & & \\
\hline 2. Having a friend killed & 163 & 44.9 & 78 & 21.5 & 0.001 \\
\hline $\begin{array}{l}\text { 3. Having a close relative } \\
\text { killed }\end{array}$ & 153 & 42.1 & 144 & 39.7 & 0.02 \\
\hline $\begin{array}{l}\text { 4. Shooting and } \\
\text { bombardment }\end{array}$ & 212 & 58.4 & 69 & 19 & 0.001 \\
\hline $\begin{array}{l}\text { 5. Arrest and kidnapping of } \\
\text { close relative }\end{array}$ & 241 & 66.4 & 48 & 13.2 & 0.03 \\
\hline $\begin{array}{l}\text { 6. Witnessing killing of a } \\
\text { friend }\end{array}$ & 68 & 18.7 & 78 & 21.5 & Ns \\
\hline $\begin{array}{l}\text { 7. Witnessing killing of a } \\
\text { relative }\end{array}$ & 68 & 18.7 & 64 & 17.6 & Ns \\
\hline $\begin{array}{l}\text { 8. Witnessing heavy artillery } \\
\text { to neighbours' house }\end{array}$ & 122 & 33.6 & & & \\
\hline $\begin{array}{l}9 . \text { Witnessing assassination } \\
\text { by rocket }\end{array}$ & 307 & 84.6 & & & \\
\hline $\begin{array}{l}\text { 10. Tank firing \& heavy artillery } \\
\text { to own home }\end{array}$ & 94 & 25.9 & & & \\
\hline 11. Firing at your home & & & 132 & 36.4 & \\
\hline 12. Being seized at home & 96 & 26.4 & 210 & 57.9 & 0.001 \\
\hline $\begin{array}{l}\text { 13. Deprivation of water \& } \\
\text { electricity }\end{array}$ & 119 & 32.8 & 200 & 55.1 & 0.001 \\
\hline 14. Beating and humiliation & 120 & 33.1 & 87 & 24 & 0.001 \\
\hline $\begin{array}{l}\text { 15. Destroying personal } \\
\text { belongings during incursion }\end{array}$ & 92 & 25.3 & 74 & 20.4 & 0.04 \\
\hline 16. Threatened to be killed & 59 & 16.3 & 50 & 13.8 & ns \\
\hline $\begin{array}{l}\text { 17. Family member threatened } \\
\text { to be killed }\end{array}$ & 62 & 17.1 & 73 & 20.1 & ns \\
\hline $\begin{array}{l}\text { 18. Threaten to be used as a } \\
\text { human shield }\end{array}$ & 59 & 16.3 & & & \\
\hline 19. Threatened to be shot at & 62 & 17.1 & 50 & 13.8 & ns \\
\hline $\begin{array}{l}\text { 20. Being arrested \& } \\
\text { kidnapped }\end{array}$ & & & 48 & 13.2 & \\
\hline 21. Own home demolished & 67 & 18.5 & & & \\
\hline $\begin{array}{l}\text { 22. Physical injury due to } \\
\text { bombardment }\end{array}$ & 56 & 15.4 & & & \\
\hline
\end{tabular}

Table 1: Percentages and frequencies of traumatic events related to Israeli military violence and Palestinian factional fighting Chi square test. not differ in the levels of PTSD, depressive and anxiety symptoms. Also only one marginal gender difference was found concerning resilience characteristics: girls reported more feelings of control than boys.

\section{The prevalence and demographic characteristics of resilient children}

The results revealed that $25.0 \%$ of the participants was classified as resilient indicating presence of high exposure to traumatic events and absence of PTSD and 22.2\% as traumatized, i.e., presence of both high exposure to trauma and occurrence of PTSD. Of the children $12.7 \%$ were classified as vulnerable, and $40.1 \%$ were spared of both high trauma and PTSD.

Table 3 illustrates how the resilience -classification varies according to the demographic factors. Family's high education was associated with high prevalence of resilient children. There were over twice as much resilient children (62.5\%) in families where father had a university education than in families with lower educational level (2628\%). Prevalence of resilience differed also between Gaza areas, being highest in the North Gaza (33\%) and Khan Yuonis (32.5\%), and lowest in the Middle area (15\%). The distribution of the resilience prevalence according to the place of residence is in Figure1, illustrating that the share of resilient children was lower in refugee camps than in towns and villages, Yet, in villages there were less traumatized children than in camps and towns.

\section{Resiliency characteristics and mental health}

Regression analyses about the protective mental health function of resilience characteristics are presented in Table 4 . The models were significant for PTSD, depressive and anxiety symptoms, explaining, however, only $10-16 \%$ of the variation. As hypothesized, the resilience characteristics of commitment, control and challenge could protect children from psychiatric symptoms when exposed to Israeli military violence. The protective function was not valid when exposed to Palestinian factional fighting. The model of Israeli military violence $\mathrm{X}$ resilience characteristics significantly contributed to PTSD (F-change in $\left.\mathrm{R}^{2}(3,374)=3.55, \mathrm{p}<0.01\right)$, depressiveness ( $\mathrm{F}$-change in $\left.\mathrm{R}^{2}(3,374)=3.02, \mathrm{p}<0.03\right)$, and anxiety (F-change in $\mathrm{R}^{2}(3,369)=$ $2.91, \mathrm{p}<0.035)$. Significant $\beta$-values indicate that exposure to Israeli military violence was less associated with PTSD $(\beta-13, \mathrm{t}=2.34, \mathrm{p}<0.05)$ and anxiety $(\beta=0 .-16, t=-2.55, p<0.01)$ among children reporting high levels of commitment. Further, exposure to Israeli military violence was relatively less associated PTSD symptoms $(\beta=-0.12, t=2.28, p<0.05)$ when showing high level of control, and with depressive symptoms $(\beta=$ $0.15, \mathrm{t}=2.43, \mathrm{p}<0.02$ ) when children show high challenge. As an example, Figure2 illustrates the protective factor of commitment on PTSD

\begin{tabular}{|c|c|c|c|c|c|}
\hline & \multicolumn{2}{|c|}{ Girls } & \multicolumn{2}{c|}{ Boys } & \\
\cline { 2 - 6 } & M & SD & M & TSD & t-tests \\
\hline Psychiatric symptoms & & & & & \\
\hline PTSD & 25.91 & 14.99 & 26.10 & 15.41 & -0.65 \\
\hline Depressive & 5.69 & 3.11 & 5.44 & 3.39 & -0.45 \\
\hline Anxiety & 3.34 & 2.26 & 3.33 & 2.69 & -0.99 \\
\hline $\begin{array}{c}\text { Resilience } \\
\text { characteristics }\end{array}$ & & & & & \\
\hline Commitment & 22.63 & 6.88 & 22.70 & 6.14 & 0.10 \\
\hline Control & 17.21 & 4.91 & 16.24 & 5.48 & $-1.82+$ \\
\hline Challenge & 17.30 & 4.53 & 16.91 & 5.40 & -0.76 \\
\hline
\end{tabular}

Table 2: Means and standard deviations of psychiatric symptoms and resilience characteristic among girls and boys. Independent $t$ test $+p<0.10$. 
Citation: Thabet AA, Tawahina AA, Punamäki RL, Vostanis P (2015) Prevalence and Mental Health Function of Resilience in Condition of Military Siege and Violence in a Palestinian Community Sample. J Psychiatry 18: 274 doi:10.4172/2378-5756.1000274

Page 5 of 9

\begin{tabular}{|c|c|c|c|c|c|c|c|c|c|}
\hline \multirow[b]{2}{*}{ Predictors } & \multicolumn{2}{|c|}{ Spared children } & \multicolumn{2}{|c|}{ Resilient children } & \multicolumn{2}{|c|}{ Vulnerable children } & \multicolumn{2}{|c|}{ Traumatized children } & \multirow[t]{2}{*}{$\beta^{2}$-values } \\
\hline & $\%$ & $\mathrm{~N}$ & $\%$ & $\mathrm{~N}$ & $\%$ & $\mathrm{~N}$ & $\%$ & $\mathrm{~N}$ & \\
\hline \multicolumn{10}{|l|}{ Gender } \\
\hline Girls & 37.8 & 70 & 25.4 & 47 & 13.5 & 25 & 23.2 & 43 & 0.69 \\
\hline Boys & 40.8 & 82 & 26.4 & 53 & 12.4 & 25 & 20.4 & 41 & \\
\hline Father education & & & & & & & & & $26.77^{* *}$ \\
\hline Preparatory school & 35.9 & 145 & 17.9 & 7 & 10.3 & 4 & 35.9 & 14 & \\
\hline Primary school & 38.2 & 29 & 26.3 & 20 & 7.9 & 6 & 27.6 & 21 & \\
\hline Secondary school & 40.6 & 54 & 27.8 & 37 & 12.8 & 17 & 18.8 & 25 & \\
\hline Polytechnic ${ }^{a}$ & 40.2 & 49 & 21.3 & 26 & 18.9 & 23 & 19.7 & 24 & \\
\hline University & 37.5 & 6 & 62.5 & 10 & 0 & 0 & 0 & 0 & \\
\hline Area in the Gaza strip ${ }^{a}$ & & & & & & & & & $27.05^{* *}$ \\
\hline North Gaza & 32.8 & 21 & 32.8 & 21 & 12.5 & 8 & 21.9 & 14 & \\
\hline Gaza City & 40.8 & 58 & 24.6 & 35 & 12.7 & 18 & 21.8 & 31 & \\
\hline Middle area & 48.1 & 26 & 14.8 & 8 & 24.1 & 13 & 13.0 & 7 & \\
\hline Khan Yunis & 26.3 & 21 & 32.5 & 26 & 11.3 & 9 & 30.0 & 24 & \\
\hline Rafah & 56.5 & 26 & 21.7 & 10 & 4.3 & 2 & 17.4 & 8 & \\
\hline Place of residency & & & & & & & & & $5.37^{\star}$ \\
\hline Town & 38.9 & 86 & 28.1 & 62 & 11.8 & 26 & 21.3 & 47 & \\
\hline Refugee camp & 42.9 & 54 & 20.6 & 26 & 15.9 & 20 & 20.6 & 26 & \\
\hline Village & 30.8 & 12 & 30.8 & 12 & 10.3 & 4 & 13.1 & 11 & \\
\hline
\end{tabular}

Note: Sample sizes differ due to missing value, ${ }^{*} p<0.05,{ }^{* *} p<0.01 ; N=386$

Table 3: Resilience-classification according to demographic variables (\%) Chi square test ${ }^{\mathrm{a}}$

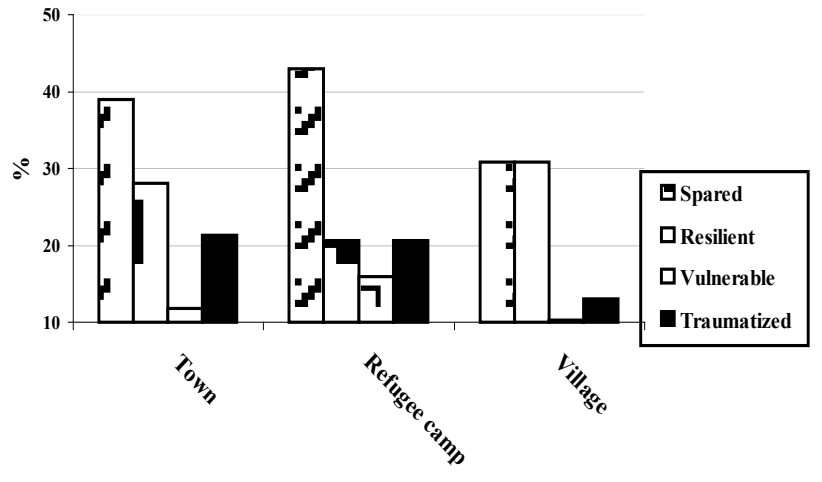

Place of residence

Figure 1: Distribution of resilience classification according to place of residency.

symptoms. The interaction effects between resilience characteristics and factional fighting on mental health were all non-significant, thus indicating that the moderating effects of commitment, control and challenge were trauma-specific.

Main effect results revealed that only Israeli military violence was significantly associated with increased levels of PTSD, depressive and anxiety symptoms, whereas exposure to the Palestinian factional fighting was not. Interestingly, there were no significant main effect of resilience characteristics on psychiatric symptoms, although the model was significant for anxiety $\left(\mathrm{F}\right.$-change in $\left.\mathrm{R}^{2}(3,372)=3.12, \mathrm{p}<.03\right)$. However, the $\beta$ for commitment, control and challenge did not reach significance. Main effects further specified that PTSD symptoms were most likely among young children from low education families, exposed to severe Israeli military violence. Low family education and military violence were associated with high level of depressive symptoms, and young age with anxiety symptoms.

\section{Discussion}

This study applies both person- and variable-based concepts of resilience among children living in life-endangering conditions and being personally exposed to military violence. First, we assess the prevalence of resilience based on the person-based classification depicting a balance between the severity of trauma and occurrence of PTSD. Second, we examine the role of resilience characteristics of commitment, control and challenge in protecting children's mental health from negative trauma impacts.

This study showed that the most common traumas were the sonic boom sounds caused by jetfighters ( $90 \%$ ), hearing of shelling by artillery $(87 \%)$ and witnessing assassination of close people by targeted rockets $(85 \%)$. Of the factional fighting, the most common traumas were hearing of shooting and gunfire in the streets (87\%) and deprivation of water or electricity (55\%). There were generally no gender differences in the exposure to traumatic events. Neither were there gender differences in the mean number of traumatic events related to Israeli military or Palestinian factional fighting. Such results were inconsistent with previous studies in the area in which boys reported more traumatic events than girls [24].

According to the DSM-IV criterion, $12.4 \%$ of the children and adolescents reported probable PTSD, and $22.37 \%$ filled the two criteria partial PTSD, and $26.7 \%$ the one criteria partial PTSD (reexperiencing or avoidance or hyper arousal). More than a third (38.4\%) of the children did not have PTSD. There were no significant differences between boys and girls in PTSD or in PTSD symptoms.

The results revealed that $25.0 \%$ of the participants was classified as resilient indicating presence of high exposure to traumatic events and absence of PTSD and $22.2 \%$ as traumatized, i.e., presence of both high exposure to trauma and occurrence of PTSD. Of the children 
Citation: Thabet AA, Tawahina AA, Punamäki RL, Vostanis P (2015) Prevalence and Mental Health Function of Resilience in Condition of Military Siege and Violence in a Palestinian Community Sample. J Psychiatry 18: 274 doi:10.4172/2378-5756.1000274

Page 6 of 9

\begin{tabular}{|c|c|c|c|c|c|c|}
\hline & \multicolumn{2}{|c|}{ PTSD-symptoms } & \multicolumn{2}{|c|}{ Depressive symptoms } & \multicolumn{2}{|c|}{ Anxiety symptoms } \\
\hline & Change $\mathrm{R}^{2}$ & $\beta^{a}$ & Change $\mathrm{R}^{2}$ & $\beta$ & Change $\mathrm{R}^{2}$ & $\beta$ \\
\hline Step 1 Background & $0.04^{* * *}$ & & $0.05^{+\cdots+*}$ & & $0.03^{* *}$ & \\
\hline Age & & $-0.14^{\prime \prime}$ & & -0.03 & & $-0.13^{*}$ \\
\hline Gender & & -0.01 & & 0.04 & & -0.01 \\
\hline Father education & & $-0.15^{* * *}$ & & $-.20^{0+\cdots+}$ & & -0.08 \\
\hline Step 2 Traumatic events & $0.05^{* \prime \prime}$ & & 0.07 & & $.03^{*}$ & \\
\hline Israeli military violence & & $.20^{+*+*+}$ & & 26 & & $0.15^{*}$ \\
\hline Palestinian factional fighting & & 0.02 & & 0.04 & . & 0.06 \\
\hline Step 3 Resilience & 0.00 & & 0.00 & & $0.02^{*}$ & \\
\hline Commitment & & 0.03 & & 0.00 & & -0.08 \\
\hline Control & & 0.01 & & -0.07 & & -0.05 \\
\hline Challenge & & -0.02 & & .01 & & -0.06 \\
\hline Step 4 Interactions I & $0.02^{*}$ & & $0.02^{*}$ & & $.02^{*}$ & \\
\hline War trauma $X$ Commitment & & $-0.13^{*}$ & & -0.05 & & $-.16^{* *}$ \\
\hline War trauma X Control & & $-0.12^{*}$ & & -0.09 & & -0.01 \\
\hline War trauma $X$ Challenge & & -0.11 & & $-0.15^{*}$ & & -0.04 \\
\hline Step 5 Interactions II & 0.01 & & 0.01 & & .001 & \\
\hline $\begin{array}{l}\text { Factional trauma } X \\
\text { Commitment }\end{array}$ & & 0.05 & & 0.08 & & -0.02 \\
\hline Factional trauma $X$ Control & & 0.03 & & -0.01 & & -0.01 \\
\hline \multirow[t]{2}{*}{$\begin{array}{l}\text { Factional trauma } \mathrm{X} \\
\text { Challenge }\end{array}$} & & 0.01 & & 0.03 & & -0.02 \\
\hline & $\begin{array}{c}E(14,365)=3.44, p<0.0001 \\
R^{2}=12 \%\end{array}$ & $\begin{array}{c}\mathrm{F}(14,371)=4.87, p<0.0001 \\
\mathrm{R}^{2}=16 \%\end{array}$ & $\begin{array}{c}E(14,371)=2.94, p<0.0001 \\
R^{2}=10 \%\end{array}$ & & & \\
\hline
\end{tabular}

Table 4: Hierarchical linear regression models for main effects of trauma and resilience characteristics and their interaction effects on psychiatric symptoms, Linear regression analysis, Note: ${ }^{*} p<0.05,{ }^{* *} p<0.01,{ }^{* * *} p<0.001,{ }^{* * * *} p<.0001,{ }^{a} \beta$-values are from the last step

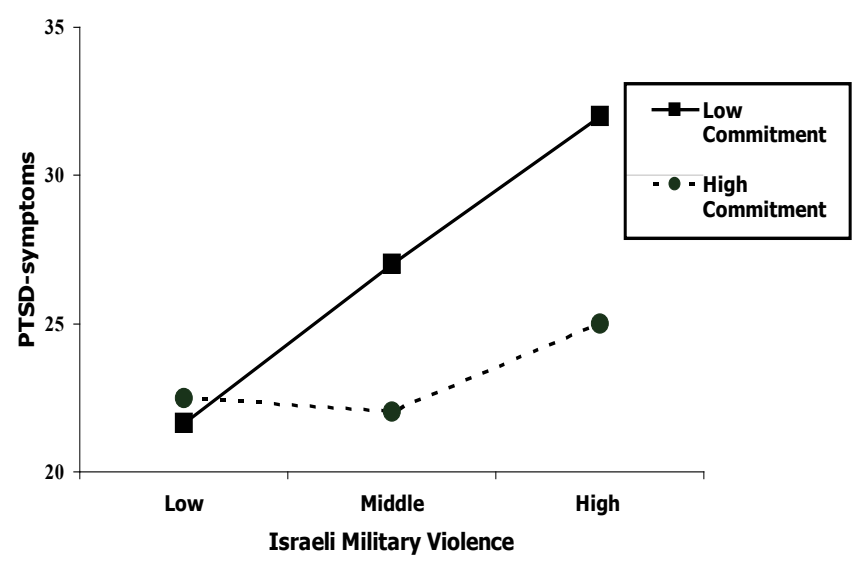

Figure 2: Military Trauma $X$ Resilience:Commitment-interaction effect on PTSD symptoms.

$12.7 \%$ were classified as vulnerable, and $40.1 \%$ were spared of both high trauma and PTSD.

Family's high education was associated with high prevalence of resilient children. There were over twice as much resilient children $(62.5 \%)$ in families where father had a university education than in families with lower educational level (26-28\%). Prevalence of resilience differed also between Gaza areas, being highest in the North Gaza (33\%) and Khan Yuonis (32.5\%), and lowest in the Middle area (15\%).

The models were significant for PTSD, depressive and anxiety symptoms, explaining, however, only $10-16 \%$ of the variation. The resilience characteristics of commitment control and challenge could protect children from psychiatric symptoms when exposed to
Israeli military violence. The protective function was not valid when exposed to Palestinian factional fighting. The model of Israeli military violence $\mathrm{X}$ resilience characteristics significantly contributed to PTSD), depressiveness, and anxiety. Significant, that exposure to Israeli military violence was less associated with PTSD and anxiety among children reporting high levels of commitment. Further, exposure to Israeli military violence was relatively less associated PTSD symptoms when showing high level of control, and with depressive symptoms when children show high challenge. Main effect results revealed that only Israeli military violence was significantly associated with increased levels of PTSD, depressive and anxiety symptoms, whereas exposure to the Palestinian factional fighting was not. Interestingly, there was no significant main effect of resilience characteristics on psychiatric symptoms, although the model was significant for anxiety. However, values for commitment control and challenge did not reach significance. Main effects further specified that PTSD symptoms were most likely among young children from low education families, exposed to severe Israeli military violence. Low family education and military violence were associated with high level of depressive symptoms, and young age with anxiety symptoms.

Most parents agree that children should be protected from war and military violence, and yet, the very habit of us adults is to solve political problems by military means. The fight between the militarily strong and technically superior Israeli army and Palestinian resistance in Gaza and West-Bank provides an example of the modern wars, characterized by excessive civilian exposure and children suffering. In this study we observed children's trauma experiences from an optimistic and more positive angle by evaluating the prevalence and function of resilience.

Most reviews on child mental health in conditions of war, terrorist attacks and disasters note that children show 'amazing' level of resilience $[38,39]$. Yet, the conclusion is predominantly based on research results showing a lack of expected psychiatric symptoms or absence 
of correlations between severity of trauma and PTSD. Our results revealed that about a quarter of Palestinian children were resilient when assessed through a balance between the exposure to severe trauma and occurrence of PTSD. Interestingly enough, the prevalence is very similar to that assessed in a random sample of Palestinian children after the First Intifada [8]. Also the share of traumatized children was similar, around $20 \%$, in the earlier and current study. In the First Intifada sample, a third of children were spared from both severe trauma and psychiatric symptoms, which is slightly less than in the current study (40\%). It corresponds with historical change of Israeli occupation forces leaving Gaza gradually after The First Intifada. Although shelling, targeted killing and siege continued, families were not daily exposed to occupation soldiers.

The long-lasting Israeli-Palestinian conflict about land and selfdetermination includes also two occasions of Palestinian 'civil war' of factional fighting. After the 1982 Lebanon war and Sabra and Shatilla massacres, fighting broke between the PLO and dissident Palestinian forces in the Tripoli refugee camps in Northern Lebanon. The context of our study was the aftermath of the second Palestinian factional fighting that took place between the Islamist Hamas and Fatah forces in the Gaza strip in June 2007. Our study is unique as it allows analysing how similar traumatic events due to either enemy army or own national groups associate with children's mental health.

There is an intuitive belief that it is psychologically easier to suffer from 'enemy fire' than to be victimized by one's own people. The meaning making process is vital in war conditions, and traumatization in the context of fighting against the oppressors can be considered heroic and worth of social support. Our results showed, however, the opposite. The experiences related to the Israeli military actions in Gaza were associated with increased PTSD and depressive and anxiety symptoms, whereas traumatic events due to the Palestinian factional fighting were not. To some extent, children reported similar trauma due to both fights, e.g., loss of close persons and witnessing killing of friends. Yet, the duration of factional fighting was few months as compared to accumulated Israeli shelling, bombardment and destruction of residential areas. However, the time window for reporting the personal exposure to violence was the same, one year. We would need more information about children's making sense of different actions of military violence. The study setting could have provided opportunity to assess perceptions of the same traumatic event in two politically different contexts, that of civil war and enemy fighting. We deserve criticism for missing this opportunity and for the absence of analyses about appraisals and meanings of different trauma.

The phenomenon of resilience involves positive and resourceful capacities, and should not be limited only to lack of symptoms. Accordingly, we conceptualized resilience also as commitment, ability to control and manage and enjoy challenges, and hypothesized that these positive resilience resources would protect children's mental health from negative trauma impacts. The hypothesis was substantiated considering PTSD, depressive and anxiety symptoms. The context of trauma was decisive for the effectiveness of resilience characteristics of commitment, control and challenge in protecting children from trauma. Their protective functioning was present only when children were exposed to Israeli military trauma. The reason may lie in the very nature of studied resilience characteristics. Research suggests that ideological commitment, especially in adolescence can protect from mental health problems in war [40]. Commitment and control are resilience characteristics that connate ideological aspects of endurance and sacrifice in the context of national struggle. One may argue that when traumatic events were caused by own Palestinian people, although in the atmosphere of execrated hatred and life threat, children and adolescents did not respond to them by stronger ideological commitment. Instead, there is some evidence that this intensified national commitment is true when personally suffering from enemy violence. Palestinian adolescents who were severely traumatized by witnessed the enemy killing friends or siblings more readily liked to join suicide bombing missions [41].

\section{Methodological Issues}

Our assessment of trauma cover events of physical violence targeted to the child (e.g., bullet wounds), witnessing violence towards a close person (e.g., witnessing killing and wounding of family member or friend), and material losses (e.g., damage to property). The score does not differentiate their relative severity, which serves criticism. We admit that witnessing a killing of a friend by enemy soldiers may signify specific age-salient pain and cannot be equated by the memory of witnessing artillery. However, majority of the assessed events of Israeli military violence and Palestinian factional fighting is highly severe and can negative impact child development [42].

Further criticism of the study relates to the conceptualizing resilience in individual terms and concentrating on child resilience characteristics. There are well-argued demands to comprise feature of family and society that enhance resilience [43] and extend the child characteristics into underlying cognitive, emotional, social and psychophysiological processes that explain the occurrence of resilience in life endangering conditions [44].

The person-based conceptualization of resilience as a typology between the trauma-disorder-balance is not without problems in a sample where we cannot find children with zero-exposure to trauma. Luckily there were enough cases to use non-PTSD group as a cutting point. The choice of the trauma cut-off points is open to criticism as we used empirical results of the accumulation of trauma as a criterion. Also for the reason of parsimony we combined traumatic events related to the Israeli military violence and Palestinian factional fighting. The choice can be criticized because our results argue for distinctive nature of trauma by revealing that the source of military violence was decisive for the protective function of resilience.

\section{Clinical Implication}

This study highlight the impact of political violence due to Israeli military violence and Palestinian factional fighting on Palestinian children mental health and resilience. Children reported PTSD, depression, and anxiety symptoms and they tried to use many ways to over such impact. Family's high education was associated with high prevalence of resilient children. Resilient was more in children where father had a university education, resilient children was lower in refugee camps than in towns and villages. Such findings increase the needs for enhancing community centres activities to deal children mental health problems by introducing new programs of using art, psychotherapy, Cognitive behaviour therapy for traumatized people. Also, increase programs which targeting parents and children and increasing their resilience in face of stress and trauma. Also, training courses for professionals working in different organization on early detection of children with mental health problems and management of such problems.

Our study may have some contribution to the field of research in findings other factors which may increase resilience in children such as 
Citation: Thabet AA, Tawahina AA, Punamäki RL, Vostanis P (2015) Prevalence and Mental Health Function of Resilience in Condition of Military Siege and Violence in a Palestinian Community Sample. J Psychiatry 18: 274 doi:10.4172/2378-5756.1000274

Page 8 of 9

social support and family support and may open new field of research in finding other risk factors for children and ways of overcome such factors.

\section{References}

1. Garmezy N (1990) "Resiliency and vulnerability to adverse developmental outcomes associated with poverty," American Behavioral Scientist 34: 416-430.

2. Luthar SS, Cicchetti D, Becker B (2000) "The construct of resilience: A critical evaluation and guidelines for future work," Child Development 71: 543-562.

3. Werner E, Smith "Vulnerable but invincible: A longitudinal study of resilient children and youth," New York: McGraw-Hill.

4. Bonnano GA (2004) “Loss, trauma, and human resilience. Have we understood the human capacity to thrive after extremely aversive events?" American Psychologist 59: 20-28

5. Ehntholt KA, Yule W (2001) "Practitioner Review: Assessment and treatment of refugee children and adolescents who have experienced war-related trauma,". J Child Psychol Psychiatry 47: 1197.

6. Vostanis $P$ (2004) "The impact, psychological sequelae and management of trauma affecting children," Current Opinion in Psychiatry 17: 269-273.

7. Zucker RA, Wong MM, Puttler LI, Fitzgerald HE (2003) "Resilience and vulnerability among sons of alcoholics. Relationship to developmental outcomes between early childhood and adolescence," In S. S. Luthar (Ed.), "Resilience and Vulnerability. Adaptation in the Context of Childhood Adversities" New York: Cambridge University Press. 76-103.

8. Punamäki RL, Qouta S, Miller T, El-Sarraj E (2011) Who are the resilient children in condition of military violence? Family- and child-related factors in a Palestinian community sample,". Peace and Conflict 17: 389-416.

9. Luthar SS, Doernberger CH, Ziegler E (1993) "Resilience is not a unidimensional construct: Insights from a prospective study of inner-city adolescents," Development and Psychopathology 5: 703-717.

10. Olsson CA, Bond L, Burns JM, Vella-Brodrick DA, Sawyer SM (2003) "Adolescent resilience: a concept analysis," J Adolesc 26: 1-11.

11. Masten AS, Hubbard JJ, Gest SD, Tellegen A, Garmezy N, et al. (1999) "Competence in the context of adversity: Pathways to resilience an maladaption from childhood to late adolescence," Dev Psychopathol 11: 143-169.

12. Waaktaar T, Christie HJ, Borge AlH, Torgersen S (2004) "How can young people's resilience be enhanced? Experiences from a clinical intervention project," Clinical Child Psychology and Psychiatry 9: 167-183.

13. Apfel RJ, Simon B (1996) "Minefields in their hearts: The mental health of children in war and communal violence," New haven, CT: Yale University Press.

14. Zimmerman MA, Arunkumar R (1994) "Resiliency research: Implications for schools and policy," Social Policy Report. Society for Research in Child Development 8.

15. Flores E, Cicchetti D, Rogosch FA (2005) "Predictors of resilience in maltreated and nonmal treated latino children," .Developmental Psychology 41: 338-351.

16. Beardslee WR, Podorefsky D (1988) "Resilient adolescents whose parents have serious affective and other psychiatric disorders: the importance of selfunderstanding and relationships," Am J Psychiatr 145: 63-69.

17. Toth SL, Cicchetti D, Jungmeen K (2002) "Relations among children's perceptions of maternal behavior, attributional styles, and behavioral symptomatology in maltreated children,". Journal of Abnormal Child Psychology 30: 487-500.

18. Ehlers A, Clark DM, Hackmann A, McManus F, Fennell M (2005) "A cognitive model of posttraumatic stress disorder," development and evaluation, "Behav Res Ther 43: 313-431.

19. Laor N, Wolmer L, Alon M, Siev J, Samuel E, et al. (2006) "Risk and Protective factors mediating psychological symptoms and Ideological commitment of adolescents facing continuous terrorism," J Nerv Ment Dis 194: 275-278.

20. Lengua LJ, Long AC, Smith KI, Meltzoff AN (2005) "Pre-attack symptomatology and temperament as predictors of children's responses to the September 11 terrorist attacks," J Child Psychol Psychiatry 46: 631-645.

21. Punamäki RL, Komproe I, Qouta S, El-Masri M, De Jong JTVM (2005) "The deterioration and mobilization effects of trauma on social support: Childhood maltreatment and adulthood military violence in a Palestinian community sample," Child Abuse Negl 29: 351-373.

22. Bonanno GA, Galea SA, Bucciarelli A, Vlahov D (2006) "Psychological resilience after disaster - New York City in the aftermath of the september 11th terrorist attack," Psychol Sci 17: 181-186.

23. Pat-Horenczyk R, Abramovitz R, Peled O, Brom D, Daie A, et al. (2007) "Adolescent exposure to recurrent terrorism in Israel: Posttraumatic distress and functional impairment,". Am J Orthopsychiatry 77: 76-85.

24. Thabet AA, Abdulla $T$, El Helou M, Vostanis $P$ "Effect of trauma on children mental health in the Gaza Strip and West Bank In C. W. Greenbaum, P. Veerman \& N. Bacon-Shnoor (Eds.), Protection of children during armed political conflict. A Multidisciplinary Perspective (pp. 123-138). London: Intersentia Publishers.

25. Luthar SS, Cushing SS (1999) "Measurement issues in the empirical study of resilience," In M. D. Glantz \& J. L. Johnson (Eds.), Resilience and development Positive life adaptations (pp. 129-160). New York: Plenum.

26. Rodriguez N, Steinberg AM, Saltzman W, Pynoos RS (2001) "The PTSD Index: Psychometric analysis of the adolescent version," Paper presented at the $17^{\mathrm{Th}}$ Annual Conference of the International Society for Traumatic Stress Studies, New Orleans, LA December.

27. Abdeen Z, Qasrawi R, Nabil S, Shaheen M (2008) "Psychological reactions to Israeli occupation: Findings from the national study of school-based screening in Palestine,". Int J Behav Develop 32: 290-297.

28. Pat-Horenczyk R, Qasrawi R, Lesack R, Haj-Yahia M, Peled O, et al. (2008) "Posttraumatic Symptoms, Functional Impairment, and Coping among Adolescents on Both Sides of the Israeli-Palestinian Conflict: A Cross-Cultural Approach," Appl Psychol, An International Review.

29. Weisenberg $M$, Schwarzwald J, Waysman $M$, Solomon $Z$, Klingman A (1993) "Coping of school-age children in the sealed room during scud missile bombardment and postwar stress reactions,". J Consult Clin Psychol 61: 462 467

30. Pynoos RS, Frederick C, Nader K, Arroy W, Steinberg A, et al. (1987) "Life threat and post-traumatic stress in school-age children," Arch Gen Psychiatry 44: 1057-1063.

31. Steinberg AM, Brymer MJ, Decker KB, Pynoos RS (2004) The University of California at Los Angeles Post-Traumatic Stress Disorder Reaction Index. Curr Psychiatry Rep 6: 96-100.

32. Kovacs M (1981) Rating scales to assess depression in school-aged children Acta Paedopsychiatrica 46: 305-315.

33. Reynolds CR, Richmond BO (1985) Revised Children's Manifest Anxiety Scale (RCMAS) Manual. Los Angele: Western Psychological Services.

34. Maekhemer E (2002) The Resilience Attitude Scale Cairo Anglo Egyptian Library 2002.

35. Doukhan N, El Hajar B (2006) Stress among the Islamic University students and its relationships with psychological hardness. Islamic University Journal 14: 369-398.

36. Aiken LS, West SG (1991) "Multiple regression: Testing and interpreting interactions," Thousand Oaks, CA: Sage Publications.

37. Palestinian Bureau of Statistics (2006) "Estimates of Quarterly National Accounts," (First Quarter 2006), Ramallah-Palestine.

38. Barenbaum J, Ruchkin V, Schwab-Stone M (2004) "The psychosocial aspects of children exposed to war: Practice and policy initiatives," J Child Psychol Psychiatry 45: 41-62.

39. Pfefferbaum $B$ (1997) "Posttraumatic stress disorder in children: A review of the Past 10 years," J Am Acad Child Adolesc Psychiatry 36: 1503-1511.

40. Shamai M, Kimhi S (2006) "Exposure of threat of war and terror, politica attitudes, stress and life satisfaction among teenagers," J Adolesc 29: 165-176.

41. Qouta S, Peltonen K, Punamäki RL, El Sarraj E (2006) "Trauma and social relations: Peer and sibling relations and their mental health function among war traumatized children," Manuscript.

42. Berger R, Pat-Horenczyk R, Gelkopf M (2007) "School-based intervention fo prevention and treatment of elementary-students' terror-related distress in Israel: A quasi-randomized controlled trial,". J Trauma Stress 20: 541-551. 
Citation: Thabet AA, Tawahina AA, Punamäki RL, Vostanis P (2015) Prevalence and Mental Health Function of Resilience in Condition of Military Siege and Violence in a Palestinian Community Sample. J Psychiatry 18: 274 doi:10.4172/2378-5756.1000274

Page 9 of 9

43. Cicchetti D, Lynch M (1993) "Toward an ecological/transactional model of community violence and child maltreatment: Consequences for children's development,". Psychiatry 96-118.
44. Luthar SS, Cicchetti D, Becker B (2000) "The construct of resilience: A critical evaluation and guidelines for future work,". "Child Dev 71: 543-562. 